\title{
Population trends and status of the Madeira Laurel Pigeon Columba trocaz
}

\author{
PAULO OLIVEIRA, MARTIN JONES, DONATO CAIRES and DILIA \\ MENEZES
}

\begin{abstract}
Summary
A survey was undertaken in 1995 to assess the conservation status of the Madeira Laurel Pigeon Columba trocaz, a threatened species endemic to the Island of Madeira. The first large scale survey was carried out 1986, following the cessation of legal hunting of the species, to provide a baseline for future monitoring of population changes. The current study therefore aims to (1) compare population size with those of 1986 and (2) employ distance sampling methods (not used in 1986) to obtain estimates of population density and size. Eighteen transects (13 repeated from the 1986 survey and five new) were conducted in the four main areas of laurel forest. Pigeon numbers had increased on nearly all transects but some of the highest increases, proportionately and often numerically, were in areas with lower numbers in 1986. We estimate the current population to be 10,400 individuals, a considerable increase since 1986 , probably due to a ban on hunting. As laurel forest habitat is now very well protected the Madeira Laurel Pigeon is relatively safe from extinction.
\end{abstract}

\section{Introduction}

Birds limited to islands are frequently susceptible to extinction and feature prominently in the list of the world's most threatened species (Grant 1998). This is the case of the Madeira Laurel Pigeon Columba trocaz (Heineken 1829), endemic to the island of Madeira. It is listed as Rare by Collar and Stuart (1985) and Groombridge (1993). Collar et al. (1994) classified it as "conservation dependent". In 1986 the species was included in Appendix 1 of the EU Wild Bird Directive, and this was the first step towards achieving a real and effective management policy for this species.

The Madeira Laurel Pigeon is restricted to areas of native laurel forest (the main trees of which belong to the Lauracea family) on the mountainous northern slopes and to a few isolated pockets in the south of Madeira (Bannerman and Bannerman 1965, Zino and Zino 1986). It was probably exceptionally plentiful before the first settlement of the Island but the loss of laurel forest and overhunting have led to a severe decline (Oliveira and Heredia 1996).

Although now well protected, the Madeiran laurel forest only covers around $15 \%$ of the island (16.000 ha) (Costa Neves et. al. 1996). All of the forest area is now included under the jurisdiction of the Parque Natural da Madeira as "Strict Nature Reserves" or "Partial Nature Reserves". As a result the problems of habitat loss, degradation and/or fragmentation have been overcome. 
The birds feed on a wide variety of food sources, from the berries of large trees to the leaves and flowers of small plants (Zino and Zino 1986, Oliveira and Jones 1995). During the winter and in the beginning of spring, they also feed on agricultural land, using those fields that are in close contact with the forest and causing significant damage to crops. Agriculture in the areas most affected is a traditional and mainly subsistence activity based on small parcels of land.

Until 1989, the birds were hunted both for sport and because of the damage they cause to crops. Although the ban on hunting was made complete in that year, illegal hunting has continued until now, probably representing, together with poisoning, the main threat to the laurel pigeon today.

The first large-scale attempt to obtain a better understanding of this species's status was made in 1986 when the population was estimated at 2,700+ birds (Jones et al. 1989). The timing of this survey was very appropriate as it was followed by the reinforcement of the protection of the pigeons and this allowed an evaluation of the success of these conservation measures. In 1995 we carried out a second survey following the same methods as in 1986 with the aim of highlighting any population changes. We also used distance sampling methods to estimate total population size.

\section{Methods}

The fieldwork took place during the last two weeks of August 1995 using a team of 10 people. Data were collected by walking line transects through areas of laurel forest and marginal forest habitats. We divided the laurel forest into four areas, each one representing a semi-isolated group of major basins. Figure 1 shows the positions of four forest areas and the approximate location of the routes taken. A short description of these routes is given in the Appendix. Censusing was carried out from sea level up to an altitude of $1200 \mathrm{~m}$. and covered primary and secondary forest and areas subject to different levels of protection. At the beginning and/or end of some routes, agricultural land and/or exotic forest were also sampled. It was impossible to site the transects randomly or even to stratify them because of the topography; most censusing was from paths set into the mountain sides.

To monitor changes in population numbers, we chose 13 of the 25 transects used on the 1986 survey, six of which were proposed as a minimum sample to monitor changes (Jones 1990). In the majority of cases each transect was walked three times by three different teams of two people (to counter any systematic observer bias). Although the observers walked continuously whilst censusing, the recording period was split into five-minute blocks (as in 1986). All contacts were included regardless of how far away the birds were.

In order to obtain as large sample sizes as possible (for estimating population density - see later), censusing was carried out during the early daylight hours, coinciding with the first of the birds' daily activity peaks (Jones et al. 1989). In 1986 data were collected at different times of day so, to facilitate a direct comparison, the 1995 results were corrected with reference to the daily activity information provided by Jones et al. (1989).

To estimate "absolute" densities of birds, distances to all contacts were estim- 


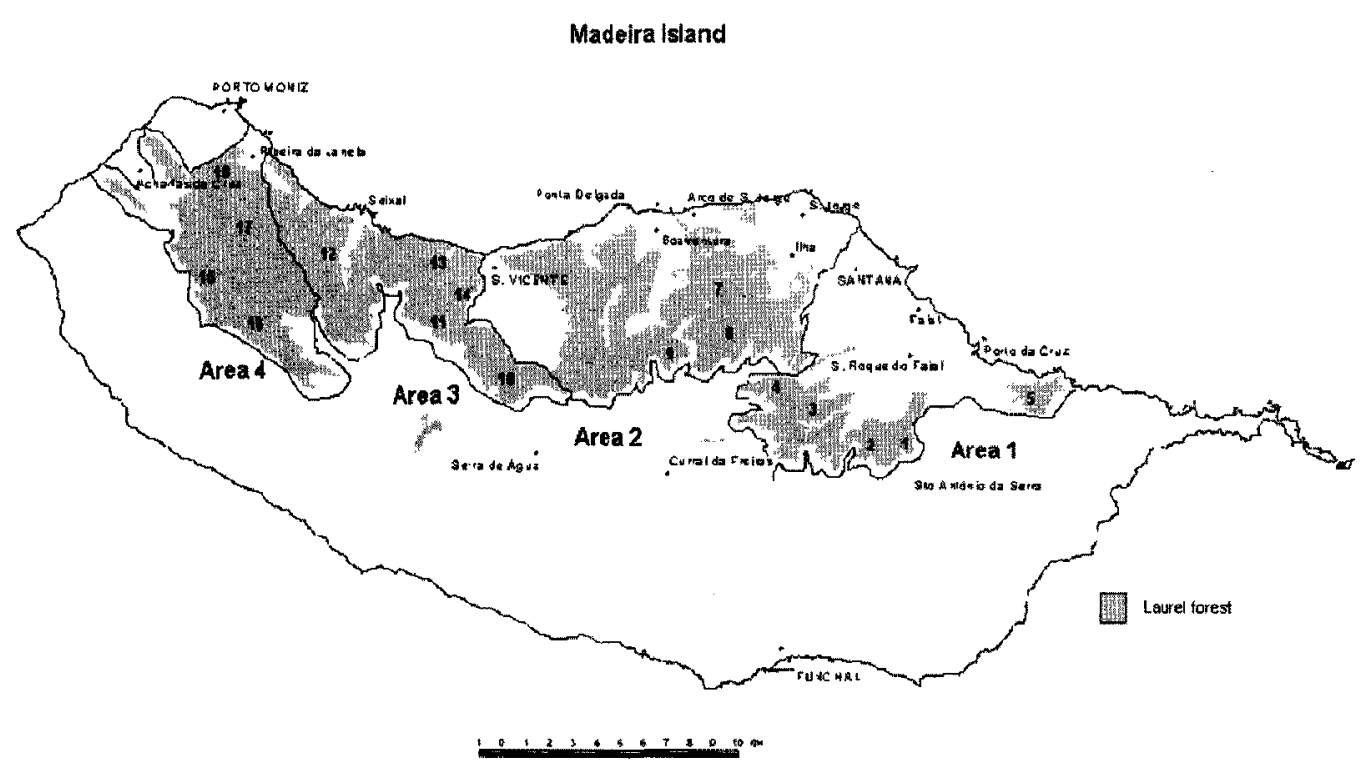

Figure 1. Map of the Island of Madeira $\left(32^{\circ} \mathrm{O} 38^{\prime} \mathrm{N}\right.$ and $16^{\circ} 54^{\prime} \mathrm{W}$ ) showing the distribution of the Laurel forest. Solid lines represent the limits of the four areas into which the forest was divided. Numbers inside these areas show the approximate location of the transects (more details are given in the Appendix and Jones, 1990).

ated on a total of 18 transect routes (the 13 mentioned above plus five new ones, see Figure 1 and Appendix). The assumption when using this distance sampling technique is that detection on or near the line walked is certain, and the chance of detection declines with distance from that line. The problem in Madeira is that the probability of detection with distance (the detection function) varies along individual transects. To overcome this, at the end of each five-minute period, detectability was assessed on a scale from one to five. A one denoted that visibility and therefore chance of detection was poor and a five that the visibility was excellent throughout most of the five-minute period. All the teams made their own scaling and we chose, for each five-minute period, the lowest value found and then only used the periods with a score higher than or equal to three. This applies only for the population estimates and not for the comparisons of 1986 with 1995.

When a perched bird was sighted, its distance to the nearest point on the path, independent of our position, was estimated to the nearest metre. For birds perched on vegetation above the ground, we estimated the distance to its perpendicular projection on the forest floor. Data from birds in flight were not used in the density analysis unless they were seen to take off within view (often as a result of our presence).

Another assumption of the method is that the distances are exact, but if errors in measurement are random and not too large, then reliable density estimates are still possible, especially if the sample size is large (Buckland et al. 1993). To make sure that this assumption was met, following an initial training period, the five principal recorders underwent a trial in which they were required to estimate the distance to 25 different objects (distances ranging between 3 and $70 \mathrm{~m}$ ). Some of biases in their performance are analysed in the results section. 

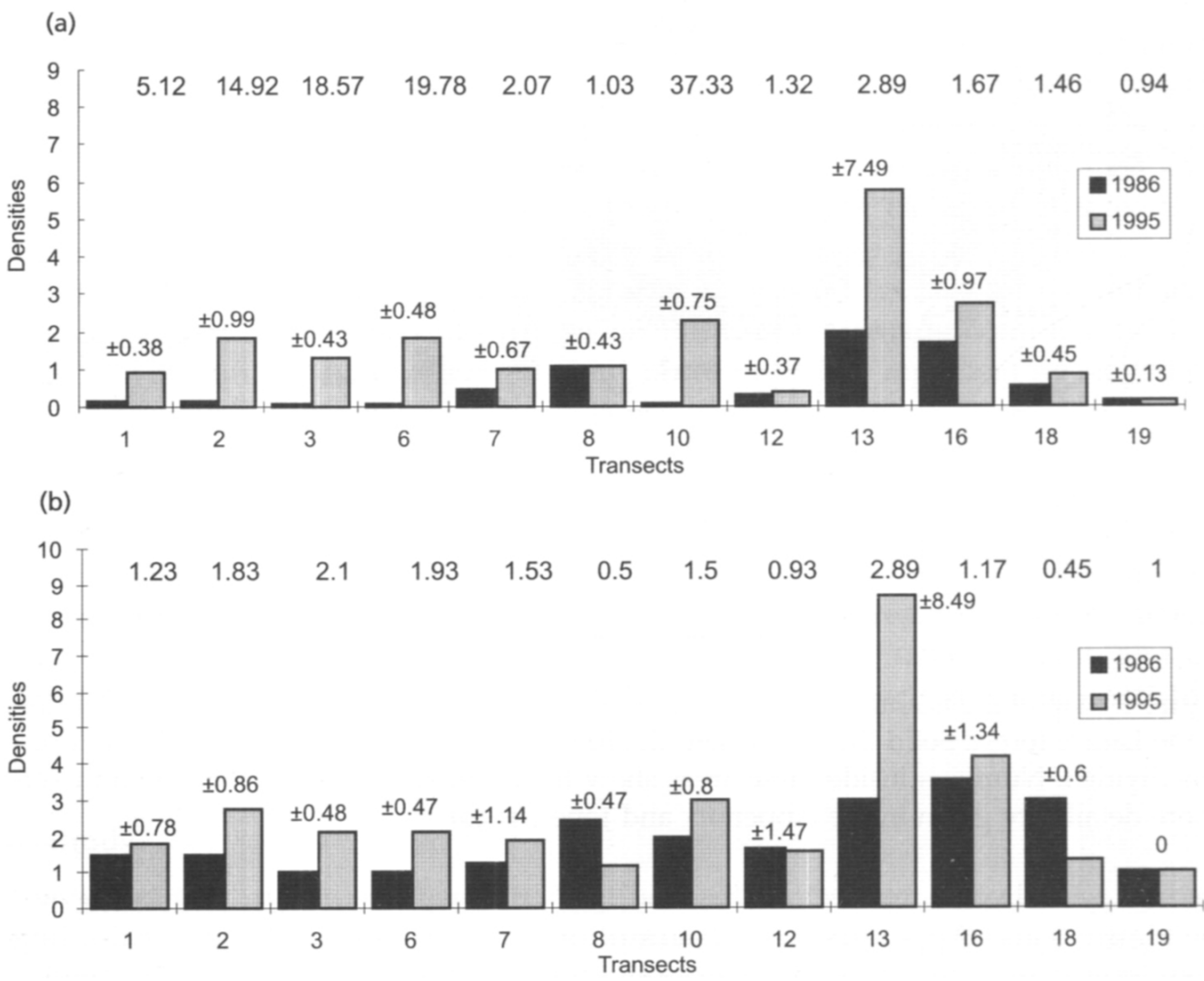

Figure 2a,b. Relative densities found for the 1986 and 1995 surveys. (a) The mean number of pigeons per five-minute walking period and (b) the mean number of pigeons per fiveminute period in the better habitat (periods where at least one bird was recorded). The numbers above the bars represent the $95 \%$ confidence intervals and the numbers on the top of each graph represent the increase rate found for each transect. (see text for explanation and Figure 1 and Appendix I for location and description of transects).

\section{Results}

Population changes 1986 to 1995

Figure 2 shows the relative and (in the case of 1995) corrected densities (average number of pigeons per five-minute period), recorded on transects in 1986 and in 1995. Figure 2a shows the average number of birds per five-minute period on all transects. These figures do not necessarily reflect the relative densities of pigeons in different areas as on some transects much more time was spent walking through suitable habitat. Following Jones et al. (1989), a more direct comparison of the density of pigeons within suitable areas is shown in Figure $2 b$ where, for each transect and both years, only the five-minute counts that recorded at least one pigeon are included.

The mean number of pigeons found in 1995 was higher for all transects, except for transect 8 , where the means are equal. This transect was located in Ribeiro Bonito, one of the best-preserved areas of laurel forest. Figure $2 b$ shows a generally similar trend, but now there are four cases where the 1986 counts are higher 


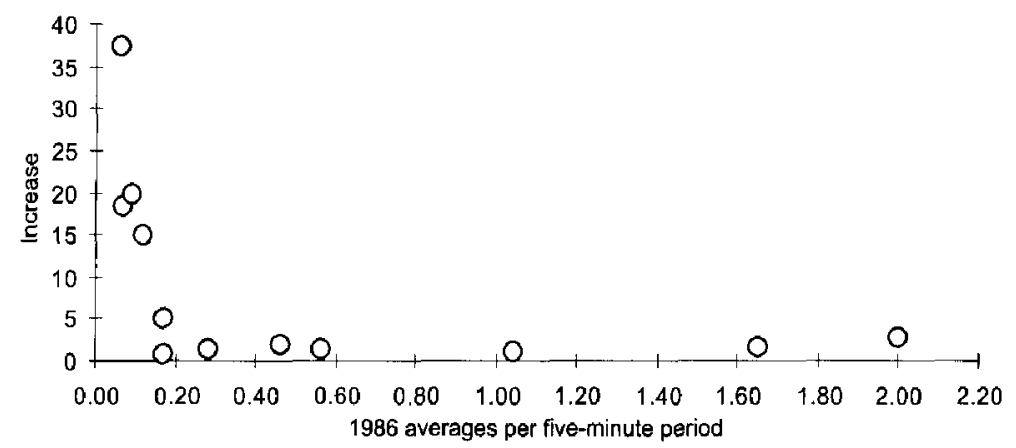

Figure 3. The relationship between the average number of pigeons per five-minute peropd found in 1986 and the rate of increase between 1986 and 1995.

than the 1995 ones. These transects are numbers 8, 12, 18 and 19 (Ribeiro Bonito, Chão da Ribeira, Ribeira da Janela (levada) and Ribeira da Ponta do Sol, respectively). Transect number 19 was located on a poor area of laurel forest on the south side of the island but the other three were located in areas of very well-preserved forest.

Although there does seem to be a general increase in numbers, it is also obvious that there are differences between transects. The rates of increase (mean number per five-minute count in 1995 divided by the 1986 figure) are shown in Figures $2 a$ and $2 b$ and the data from "all" counts are plotted in Figure 3 against the mean number of pigeons found in 1986. The transects with the lowest densities in 1986 have the highest rates of increase. This trend for the more marginal habitats to exhibit higher increases is confirmed when the "all" and "good" data sets are compared: the former have significantly higher increase rates than the latter (Mann-Whitney $\mathrm{U}_{12,12}=36.5 ; P<0,05$ ).

\section{Accuracy of the distance estimates}

A runs test showed that none of the observers had a significant tendency to make any systematic error, i.e. none of the observers systematically under- or overestimated the distances $(Z=0.74, P=0.45 ; Z=1.39, P=0.16 ; Z=1.60, P=0.11$; $Z=1.21, P=0.22 ; Z=0.28, P=0.78)$. The mean absolute deviation of the distance estimates was 0.72 at between 3 and $10 \mathrm{~m}, 2.2 \mathrm{~m}$ at between $20 \mathrm{~m}$ and $30 \mathrm{~m}, 8.5$ $\mathrm{m}$ at between $40 \mathrm{~m}$ and $50 \mathrm{~m}, 11.22 \mathrm{~m}$ at between $60 \mathrm{~m}$ and $70 \mathrm{~m}$. The majority of contacts with pigeons were at distances of less than $40 \mathrm{~m}$ so we suggest that the errors were indeed relatively small and random.

\section{Population density and size}

Table 1 shows the density per square kilometre and the abundance of birds in each of the four areas into which our survey was divided. The highest density was found in Area 3 (S. Vicente Este e Ribeira de S. Jorge) where we have almost 100 birds $/ \mathrm{km}^{2}$, the lowest is Area 4 (Fajã da Nogueira e Funduras) with 31 birds/ $\mathrm{km}^{2}$. Adding the number of birds per area we calculate a total population of 10,400 individuals, which represents a more than threefold increase over the 1986 estimate. 
Table 1 . Densities per $\mathrm{Km}^{2}$ and the abundance on each of the four areas into which our survey was divided

\begin{tabular}{|c|c|c|c|c|c|}
\hline $\begin{array}{l}\text { Area } \\
\text { (cover of forest) }\end{array}$ & $\begin{array}{l}\text { Sample size } \\
\text { transects }(n)\end{array}$ & $\begin{array}{l}\text { E.S.W. }{ }^{\mathrm{a}} \\
\text { (95\% conf. } \\
\text { intervals) }\end{array}$ & $\begin{array}{c}\text { Model } \\
\text { selected }^{\mathrm{b}}\end{array}$ & $\begin{array}{l}\text { Density } \\
\text { per } \mathrm{km}^{2} \\
(95 \% \mathrm{CI})\end{array}$ & $\begin{array}{l}\text { Abundance } \\
(95 \% \mathrm{CI})\end{array}$ \\
\hline $\begin{array}{l}\text { 1. Fajã da Nog- } \\
\text { ueira e Fund- } \\
\text { uras ( } 16.4 \\
\mathrm{~km}^{2} \text { ) }\end{array}$ & $7(93)$ & $63.8(49.6 ; 81.9)$ & $\begin{array}{l}\text { Hazard/ } \\
\text { polynomial }\end{array}$ & $31(1.9 ; 5.1)$ & $508(303 ; 814)$ \\
\hline $\begin{array}{l}\text { 2. S.Vicente Este e } \\
\text { Rib. de } \mathrm{S} \text {. } \\
\text { Jorge }(66.6 \\
\left.\mathrm{km}^{2}\right)\end{array}$ & $13(92)$ & $74.0(57.5 ; 95.7)$ & $\begin{array}{l}\text { Half-normal/ } \\
\text { cosine }\end{array}$ & $99(5.5 ; 17.9)$ & $6599(3661 ; 1917)$ \\
\hline $\begin{array}{l}\text { 3. Rib. do Seixal e } \\
\text { S.Vicente } \\
\text { Oeste }(31.1 \\
\left.\mathrm{km}^{2}\right)\end{array}$ & $9(112)$ & $27.6(17.0 ; 45.0)$ & Hazard/cosine & $37(1.9 ; 6.9)$ & $1149(615 ; 2144)$ \\
\hline $\begin{array}{c}\text { 4. Rib. da Janela } \\
\left(35.8 \mathrm{~km}^{2}\right)\end{array}$ & $11(109)$ & $56.2(42.5 ; 74.4)$ & $\begin{array}{c}\text { Hazard / } \\
\text { polynomial }\end{array}$ & $59(3.8 ; 9.2)$ & $2116(1302 ; 3096)$ \\
\hline Total population: & & & & & $10359(5,875 ; 7,977)$ \\
\hline
\end{tabular}

${ }^{a}$ Effective strip width (metres).

${ }^{b}$ The models for the detection function are selected based on their relative performance in relation to each data sub-set (for details refer to Buckland et al. 1993)

\section{Discussion}

Our first major conclusion is that the Laurel Pigeon population has increased between 1986 and 1995. The increase has occurred all over the island but is proportionately and often numerically greater in the areas which supported lower densities in 1986 (apart from transect 13). The simplest explanation is that as population size increases a density-dependent mechanism leads to greater use of more marginal areas. Habitats which are intrinsically less suitable may be quite tolerable if population densities there are lower than in prime habitats (Cody 1985). Since the laurel forest occurs in discrete patches between which the different tree species do not have a homogeneous distribution (Costa Neves et al. 1996), it is likely that they will vary in attractiveness to pigeons.

Although at the time of the survey there were differences in densities between transects and also between areas, this may not be a permanent feature. Fruiteating birds generally have to deal with strong spatiotemporal patterning that will affect the way they use their habitat (Herrera 1985) and subtle changes in resources such as berry density may promote changes in habitat use (Cody 1985). Although the Laurel Pigeon is not an exclusive frugivore, we know that at the time of the year at which our surveys were conducted, the berries of the bay tree Laurus azorica play an important role on this bird's habitat selection (Oliveira and Jones 1995). The existence of a wide year-to-year variability in fruit production of some Lauraceae has been shown for other forests (Wheelwright 1986) and there is strong evidence that we have the same situation in Madeiran laurel forest (Oliveira and Jones 1995). Thus the pattern of habitat occupancy we have recorded is likely to vary both within and between years.

Seasonal and annual changes in habitat use may also affect comparisons of the 
four major forest blocks. However, the considerably higher densities found in areas 2 and 4 and the greater areas of laurel forest within these areas suggest that they will always be of critical importance for the preservation of the pigeon.

Our total population estimate of 10,400 individuals suggests a considerable increase over the $2,700+$ birds estimated in 1986 . The earlier estimate may not be particularly reliable but the comparison of the transects covered in both years confirms that there has been a significant increase. It is possible that natural fluctuations may be responsible for this change but we suggest that the ban on hunting has made an important contribution. In the last legal shooting period five consecutive Sundays in January and February 1985 - in just one site (Chão da Ribeira), one party of four guns shot 64 birds in four days and over 140 were shot in this valley during the five Sundays (Zino and Zino 1986). If this level of hunting occured in just a few other areas (and according to Zino and Zino (1986) it probably did) then more than $20 \%$ of the population could have been lost. The ban on hunting may therefore have removed one of the major constraints on population growth.

Our general conclusion is that with a population of over 10,000 individuals (or even the lower confidence limit of 5,875 ) and habitat loss and hunting under control, the Madeira Laurel Pigeon is relatively secure. However, the species's "conservation dependent" status is still appropriate as other threats remain, namely illegal shooting and poisoning and particularly, predation of eggs and nestlings by rats Rattus rattus (Oliveira and Heredia 1996). Recent studies in the Canary Islands show that this type of predation is responsible for the low breeding success of both the Bolle's Laurel Pigeon Columba bollii and the White tailed Laurel Pigeon Columba junoniae (Hernandez et al. 1999).

In Madeira, rats are found at high densities in laurel forest (foraging in the canopy of even the tallest trees) and the steep-sided ravines with sparser vegetation (A. Easby, pers. comm.). Considering that the Madeira Laurel Pigeon builds its nest in forest trees and in cavities in cliffs (Bannerman and Bannerman 1965, Zino 1969, Cramp 1985), it would be surprising if rat predation does not have some effect on breeding output. Further research on this is obviously needed.

As long as the appropriate procedures are adopted (allowing for the variation in visibility) we suggest that distance sampling or particularly the "variable distance line transect method" we used is appropriate for use in this type of terrain. Although the transect routes should not ideally follow existing paths or habitat features, in Madeira we had little choice. However, the paths that we primarily used have very little impact on the vegetation. Even though the estimates produced have quite large confidence intervals they are certainly more reliable than the previous tentative guesses (Zino and Zino 1986, Jones et al. 1989, Oliveira and Jones 1995). The total population estimate is essential for confirming the conservation status of the species and, in combination with the comparison of encounter rates on transects between years, assessing population changes. With this in mind we recommend that the monitoring scheme begun in 1986 be continued. The minimum sample could be the one proposed by Jones et al. (1989) but we strongly believe that, due to the conditions under which the work is carried out, the repeat of all the transects presented on this paper would provide more reliable information. Distance sampling techniques and procedures described here should be used again on future surveys. 


\section{Acknowledgements}

Thanks to all the members of our "field team" specially to Bethan Cox, Dylan Walker, Matt Sutton and Simon Eaves without whom this intensive survey would have been impossible. The other members of the team were Bernardo Faria, Emanuel Spinola, Filipe Caldeira, Isamberto Silva, Luisa Fernandes and Paulo Moniz. Thank to Eng. Henrique Costa Neves for support. This work was partially financed through an E.C. Life project.

\section{Appendix I. Transect routes.}

Location and details of the transects that are common to both surveys can be found in Jones (1990). For practical reasons 1986 survey transect numbers were changed as it follows: 6 to $16 ; 7$ to $15 ; 9$ to $2 ; 10$ to $3 ; 11$ to $6 ; 15$ to $7 ; 17$ to $10 ; 19$ to $8 ; 20$ to $13 ; 23$ to $19 ; 25$ to 18 . Only the location and details of the transects that were carried out in 1995 are shown here.

\begin{tabular}{|c|c|c|c|c|}
\hline \multicolumn{2}{|c|}{ Transect number/description } & \multirow{2}{*}{$\begin{array}{l}\begin{array}{c}\text { Altitude (m) } \\
\text { (start/end) }\end{array} \\
1050 / 1050\end{array}$} & \multirow{2}{*}{$\begin{array}{c}\begin{array}{c}\text { Length } \\
(\mathrm{km})\end{array} \\
3.4\end{array}$} & \multirow{2}{*}{$\begin{array}{c}\begin{array}{c}\text { Walking time } \\
\text { (in } 5 \text { minute } \\
\text { units) }\end{array} \\
14\end{array}$} \\
\hline 4 & $\begin{array}{l}\text { Ribeira Seca to Ribeira das Lages along the } \\
\text { "Levada" da Serra do Faial }\end{array}$ & & & \\
\hline 5. & $\begin{array}{l}\text { Casa da Água above Fajã do Penedo to Ribeira } \\
\text { João Fernandes along "Levada" dos Tornos }\end{array}$ & $510 / 510$ & 3.6 & 15 \\
\hline 11. & $\begin{array}{l}\text { Casa da Agua das Ginjas to Ribeira do Seixal } \\
\text { along the "Levada" do Norte }\end{array}$ & $1010 / 1010$ & 1.8 & \\
\hline 14. & $\begin{array}{l}\text { Paul da Serra to Montado dos Pessegueiros } \\
\text { down the walking track }\end{array}$ & $1200 / 25$ & $5 \cdot 7$ & 23 \\
\hline 15. & $\begin{array}{l}\text { From Rabaçal do Galhano along Ribeira da } \\
\text { Janela river bed. }\end{array}$ & $850 / 480$ & 4.1 & 24 \\
\hline
\end{tabular}

\section{References}

Bannerman, D.A. and Bannerman, W.M. (1965) Birds of the Atlantic. Edinburgh: Oliver and Boyd.

Buckland, S.T., Anderson, D.R., Burnham, K.P. and Laake, J.L. (1993) Distance sampling. Estimating abundance of biological populations. London: Chapman and Hall.

Cramp. S. (1985) The birds of the Western Paleartic Vol. IV. Oxford, U.K.: Oxford University Press.

Cody, M. (1985) An Introduction to habitat selection in birds. Pp. 4-46 in M. Cody, ed. Habitat selection in birds. New York: Academic Press.

Collar, N.J. and Stuart, S.N. (1985) Threatened birds of Africa and related Islands. The ICBP / IUCN Red data Book, part 1. Third edition. Cambridge, U.K.: International Council for Bird Preservation and International Union for Conservation of Nature and Natural Resources.

Collar, N.J., Crosby, M.J. and Stattersfield, A.J. (1994) Birds to watch 2: the world list of threatened birds. Cambridge, U.K.: BirdLife International (BirdLife Conservation Series No. 4).

Costa Neves, H., Valente, V., Faria, B., Silva, I., Marques, J., Gouveia, N., Silva, P. and Oliveira, P. (1996) Laurissilva da Madeira. Caracterizão quantitativa e qualitativa. Funçal: S.R.A.F.P. - Parque Natural da Madeira.

Grant, P. (1998) Evolution on islands. Oxford, U.K.: Oxford University Press

Groombridge, B. (1993) 1994 IUCN Red List of threatened animals. Gland, Switzerland, and 
Cambridge, U.K.: International Union for Conservation of Nature and Natural Resources.

Heineken, C. (1829) Notice of some of the birds of Madeira. Edinb. J. Sci. 2: 229-233.

Hernandez, M., Martin, A. and Nogales, M. (1999) Breeding success and predation on artificial nests of the endemic pigeons Bolle's Laurel Pigeon, Columba bollii, and Whitetailed Pigeon, Columba junoniae in the laurel forest of Tenerife (Canary Islands) Ibis. 141: 52-59

Herrera, C. (1985) Habitat-consumer interactions in frugivorous birds. Pp. 341-359 in M. Cody, ed. Habitat selection in birds. New York: Academic Press.

Jones, M.J. (1990) A survey of the distribution and habitat preferences of the long-toed pigeon, Columba trocaz in Madeira. Bol. Mus. Mun. Funchal. 42 (219): 71-86.

Jones, M.J., Hamer, K., Hill, J., Hounsome, M.V., Jepson, P., Lace, L.A., Read, H. and Turtle, C. (1989) A survey of distribution and habitat preferences of the long-toed pigeon Columba trocaz in Madeira. Cambridge, U.K.: International Countil for Bird Preservation (Study report 32).

Morris, W.D. (1987) Ecological scale and habitat use. Ecology 68: 362-369.

Oliveira, P. e Heredia, B (1996) Action plan for the Madeira Laurel Pigeon, Columba trocaz. Pp. 303-309 in L. Rose Heredia, and M. Painter, eds. Globally threatened birds in Europe. Action plans. Strasbourg, France: Council of Europe Publishing.

Oliveira, P. and Jones, M. (1995) Population numbers, habitat preferences and the impact of the long-toed pigeon, Columba trocaz, on agriculture. Bol. Mus. Mun. Funchal 4: 531542.

Wheelwright, N.T. (1986) A seven-year study of individual variation in fruit production in tropical bird-dispersed tree species in the family Lauraceae. Pp. 19-35 in A. Estrada and T. Fleming, eds. Frugivores and seed dispersal. Boston: Junk.

Zino, F. and Zino, P. A. (1986) An account of the habitat, feeding habitats, density, breeding and need of protection of the Long-toed Wood Pigeon Columba trocaz. Bocagiana. 88: $1-16$.

Zino, P.A. (1969) Observations sur Columba trocaz. Oiseau Rev. Fr. Om. 39: 261-264

\section{PAULO OLIVEIRA}

Parque Natural da Madeira, Quinta do Bom Sucesso, Caminho do Meio, go5o Madeira, Portugal.

\section{MARTIN JONES}

Manchester Metropolitan University, John Dalton Building, Chester Street, Manchester M1 5GD, U.K.

DONATO CAIRES

Rua do Agrela No. 10. 9050 Madeira, Portugal.

DILIA MENEZES

Parque Natural da Madeira, Quinta do Bom Sucesso, Caminho do Meio, 9050 Madeira, Portugal. 